\title{
One Pot Synthesis of Formyl Phenyl Terpyridine: A Simplified Synthesis
}

\author{
ANUP GURUNG and SANJAY DAHAL* \\ Department of Chemistry, Sikkim Manipal Institute of Technology, \\ Sikkim Manipal University, East Sikkim- 737136, India. \\ ${ }^{*}$ Corresponding author E-mail: dahal.sanjay@smit.smu.edu.in
}

http://dx.doi.org/10.13005/ojc/320253

(Received: February 29, 2016; Accepted: April 02, 2016)

\begin{abstract}
Formyl phenylterpyridinewas synthesized from methyl phenylterpyridine using $\mathrm{SeO}_{2}$ as the oxidizing agent. $\mathrm{SeO}_{2}$ conventionally has been used to oxidize allylic and aliphatic methyl groups. The simple conversion of methyl group attached to aromatic ring appended to heterocycle in a clean one pot synthesis paves way for synthesis of similar aldehydes extendable to other classes of compound as well.
\end{abstract}

Keywords: Methyl phenylterpyridine (4-methyl-phenyl-2,2':6',2"-terpyridine), Formylphenylterpyridine(4-formyl-phenyl-2,2':6',2"-terpyridine)", Oxidation, Selenium dioxide.

\section{INTRODUCTION}

Aldehydes are the versatile reagents in the organic synthesis and especially aromatic aldehydes has been extensively used as a starting reagent for various products through various types of reactions ${ }^{1-4}$.Synthesis of Oximes which are known for their biological activity from aldehydes has been reported in the literature ${ }^{5}$. Recently the synthesis of aryl amines from aldehydes which has pharmaceutical importance has been reported using $\mathrm{Zn}\left(\mathrm{BH}_{4}\right)_{2} /$ $\mathrm{MgBr}_{2}{ }^{6}$.Varieties of oxidizing agents are available for oxidation of aliphatic as well as aromatic alkyl groups which gets converted to carboxylic group in majority of the reactions ${ }^{7}$. Mild oxidizing agents has been used to oxidize methyl group to alcohol. Variety of reagents convert methyl group to aldehyde. Methods like Etard reaction, chromyl chloride oxidation and oxidation with PCC involve multistep reactions for conversion ${ }^{8-11}$. Cerium and Iridium catalyzed reaction can oxidize methyl group attached to aromatic group like benzene ${ }^{12-15}$ but is not successful in oxidizing methyl groups attached to heterocyclic rings. Selenium dioxide is a versatile reagent for oxidizing methyl groups directly attached to heterocyclic ring like 3-methylbipyridine, 4-methylphenantrholine, 2,5-dimethylpyridine ${ }^{16}$. Heterocyclic aldehydes are best known for their versatility in the synthesis of 
biologically active molecules. But the problem arises when there is a aromatic ring like phenyl ring present in between heterocycle and the methyl group. Almost all the reported methods failed to oxidise such methyl groups. Schubert et al. reported the oxidation of such methyl group to aldehyde in a multistep process ${ }^{17,18}$. $\mathrm{SeO}_{2}$ was found to be unsuccessful in oxidation of methyl group of nitro toluene and even that of 2,4,6trinitrotoluene, however on conversion to phenyl bromides conversion to aldehyde was found to be feasible ${ }^{19}$. Here we report the simplified synthesis of aldehyde (FPT) in one pot using $\mathrm{SeO}_{2}$ in 1,4-dioxane paving the way for simplified oxidation of such class of compounds to aldehydes.

\section{EXPERIMENTAL}

\section{Methyl phenyl terpyridine [1] (MPT)}

was prepared using Krohnke methodology by condensation of 2-acetyl pyridine and p-tolualdehyde in $60 \%$ yield. $1.65 \mathrm{~g}(41 \mathrm{mmol})$ of crushed $\mathrm{NaOH}$ was added to the $30 \mathrm{ml}$ of Polyethylene Glycol (PEG300 ) with constant stirring at room temperature. $5 \mathrm{~g}$ (41.6mmol) of 2-acetyl pyridine was added and after 10 minutes $2.472 \mathrm{~g}(20.6 \mathrm{mmol})$ of $\mathrm{p}$ - tolualdehyde was added with continuous stirring. The colorless solution turned to light yellow. After two hours the color changed to orange and then to pink. $25 \mathrm{ml}$ of liquid $\mathrm{NH}_{3}(18 \mathrm{~N})$ was added. The white precipitate formed was washed with water and recrystallized from ethanol.
Yield \%- 60\%, HNMR-(CDCl${ }_{3}, 400 \mathrm{MHz}$, ppm) 2.4 (s, 3 H) $\delta 7.49$ (m,2 H), 8.01 (m, $2 \mathrm{H}), 8.15$ (m, 4H), $8.72(\mathrm{~d}, 2 \mathrm{H}), 8.80(\mathrm{~d}, 2 \mathrm{H}), 8.98(\mathrm{~s}, 2 \mathrm{H}), .5$, UV-Vis- $281 \mathrm{~nm}$

\section{Formyl phenylterpyridine[2] (FPT)}

$1 \mathrm{~g}(9.0 \mathrm{mmol})$ of $\mathrm{SeO}_{2}$ and $0.1 \mathrm{ml}(5.55$ $\mathrm{mmol})$ of $\mathrm{H}_{2} \mathrm{O}$ was added to 700 (2.16mmol) $\mathrm{mg}$ of MPT in $10 \mathrm{ml}$ of 1,4-dioxane. The mixture was heated at $200^{\circ} \mathrm{C}$ in autoclave for 2 hours. The steel bomb was taken out and cooled to room temperature. Additional $1 \mathrm{~g}$ of $\mathrm{SeO}_{2}$ and $0.5 \mathrm{ml}$ of $\mathrm{H}_{2} \mathrm{O}$ was added and the steel bomb was heated in autoclave for $6 \mathrm{hrs}$. The steel bomb was cooled to room temperature and the pale yellow colored product formed was dried on water bath. The product was purified by column chromatography using $\mathrm{CHCl}_{3}$ and $9: 1 \mathrm{CHCl}_{3}: \mathrm{MeOH}$ mixture as the eluent.

Yield - 20\%, ${ }^{1} \mathrm{HNMR}\left(\mathrm{CDC}_{13}, 400 \mathrm{MHz}, \mathrm{ppm}\right)$ $\delta 7.39$ (m,2 H), $7.91(\mathrm{~m}, 2 \mathrm{H}), 8.05(\mathrm{~m}, 4 \mathrm{H}), 8.69$ (d, $2 \mathrm{H}), 8.75(\mathrm{~d}, 2 \mathrm{H}), 8.78$ (s, $2 \mathrm{H}), 10.12(\mathrm{~s}, 1 \mathrm{H}) .5$, UV-Vis, $283 \mathrm{~nm}$.

\section{RESULT AND DISCUSSION}

Several reactions were carried out using different amount of $\mathrm{SeO}_{2}$ to obtain maximum conversion. As per the Table 1. large scale synthesis of aldehyde using higher concentration failed to yield any product even after keeping the reaction mixture
2<smiles>CC(=O)c1ccccc1</smiles>

2-acetyl pyridine<smiles>Cc1ccc(C=O)cc1</smiles>

p-tolualdehyde
[1]

Fig.1: Synthesis of Methyl Phenyl Terpyridine following Krohnke Methodology 
<smiles>Cc1ccc(-c2cc(-c3ccccn3)nc(-c3ccccn3)c2)cc1</smiles>

[1]

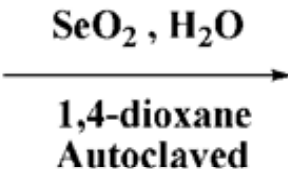<smiles>O=Cc1ccc(-c2cc(-c3ccccn3)nc(-c3ccccn3)c2)cc1</smiles>

[2]

Fig. 2: Autoclave synthesis of FormylPhenylTerpyridine from Methyl PhenylTerpyridine using $\mathrm{SeO}_{2}$ as oxidant

Table 1: Standardization of the synthesis of FormyIPhenyl Terpyridine

\begin{tabular}{lcccccc}
\hline $\begin{array}{l}\text { MPT } \\
\text { mmols }\end{array}$ & $\begin{array}{c}\mathbf{S e O}_{2} \\
\mathbf{m m o l s}\end{array}$ & $\begin{array}{c}\mathbf{1 , 4 - D i o x a n e} \\
\mathbf{m l}\end{array}$ & $\begin{array}{c}\mathbf{H}_{\mathbf{2}} \mathbf{O} \\
\mathbf{m m o l s}\end{array}$ & $\begin{array}{c}\text { Temp. } \\
{ }^{\circ} \mathbf{C}\end{array}$ & $\begin{array}{c}\text { Time } \\
\mathbf{h}\end{array}$ & $\begin{array}{c}\text { Yield } \\
\%\end{array}$ \\
\hline 6.31 & 9.00 & 35 & 11.1 & 120 & 12 & 0 \\
0.30 & 1.15 & 10 & 5.55 & 125 & 12 & 0 \\
0.30 & $1.15+{ }^{*} 1.15$ & 10 & $5.55+{ }^{*} 5.55$ & 125 & $2+{ }^{*} 8$ & 10 \\
0.30 & $1.80+{ }^{*} 1.80$ & 16 & $2.77+{ }^{*} 2.77$ & 150 & $2+{ }^{*} 10$ & 9 \\
2.16 & $4.50+{ }^{*} 4.50$ & 10 & $5.55+{ }^{*} 5.55$ & 200 & $2+{ }^{*} 6$ & 20 \\
\hline
\end{tabular}

*Time after addition of additional amount of $\mathrm{SeO}_{2}$ and $\mathrm{H}_{2} \mathrm{O}$.

at $120^{\circ} \mathrm{C}$ for 12 hours. Even in low concentration the reaction failed and no product was detected. Upon slight modification of the reaction condition i.e. changing from one time addition to two time addition of oxidizing agents after an interval resulted in formation of desired product. It can be inferred with ample support from literature that in the first step of reaction the methyl group gets converted to alcohol group which in next step gets converted to the desired formyl group. Molar ratio of $\mathrm{SeO}_{2}: \mathrm{MPT}: \mathrm{H}_{2} \mathrm{O}$ in proportion of 3/2:1:5 gave the best yield. Though small amount of unreacted MPT was detected it was reused for further reaction. The study also suggests that at the optimal temperature of $200^{\circ} \mathrm{C}$, the yield is best and the reaction time required for second step of reaction could be reduced to 6 hours. The method opens up the new route for the oxidation of tolyl group attached to heterocycle to aldehyde in one pot synthesis which otherwise is not possible in normal conditions. Though the conversion was standardized with only one heterocycle it can be easily extended to other heterocycles. 1,4-dioxane was chosen on the basis of solublity of the initial/ reactants.

The aldehyde prepared has been successfully used for the synthesis of porphyrin as revealed by UV-vis spectroscopy and detailed characterization of which is under progress.

\section{ACKNOWLEDGEMENT}

The authors would like to thanks the DST, Gov. of India for financing the research with Grant No. DST:SR/S1/IC-08/2006. 


\section{REFERENCES}

1. Aspinall, H. C; Greeves, N; Valla,C., Org. Lett.,2005, 7, 1919-1922;

2. Duan,X.-F. ; Feng, J.-X. ; Zi,G.-F; Zhang,Z.-B, Synthesis, 2009,2, 277-282;

3. Takenaka,N.; Xia,G; Yamamoto,H, J. Am. Chem. Soc., 2004, 126, 13198-13199

4. Corey,E. J.; Gilman,N.W.; Ganem,B., E. J. Am. Chem. Soc.1968; 90, 5616-5617

5. Ghozlojeh, N. ;Setamidideh, D., Orient. J. Chem.,2015, 31, 1823-1825

6. Mahmoudi, M; D, Orient. J. Chem., 2015, 31, 1215-1218

7. Dash S.; Patel S.; Mishra,B. K., Tetrahedron, 2008, 65, 724

8. Ho, T. L., Synthesis, 1972, 7, 347-354

9. Hwu,J.R.;King,K.Y,Current Science,2001, 81, ,1043-1053

10. Wheeler,O.H.,Can. J. Chem. ,1958,36, 949951
11. Ratcliffe,R. W. Org. Synth.;,1988,6 , 373375

12. Ho,T.L.; Mijs,W.J; de Jonge C.R.H ,Organic Synthesis by Oxidation With Metal Compounds, Plenum, New York, 1986. 569-631.

13. Nair,V.; Balagopal,L.; Rajan,R. Mathew,J.; Accounts Chem. Res.,2004,37,21-30.

14. Demappa, M.T., J. Appl. Polym. Sci.,2006, 103,3498-3505.

15. Jiang,B. ; Feng, Y. ; Ison,E.A. , J. Am. Chem. Soc. ,2008, 130, 14462-14464

16. Trump,E. L.; ZhouM.X, Transactions of the Kansas Academy of Science,1903, 96, 167180

17. Winter,A.; Egbe,D. A. M.; SchubertU. S., Organic Letters, 2007, 9,2345-2348 .

18. Collin, J.-P.; Heitz, V.; Sauvage, J.-P. Tetrahedron Lett.1991, 32, 5977-5980.

19. Fischer,C. H. Auration of Aromatic Nitriles, 1934,56, 2056-2057. 